ISSN: 2231-3354

Received on: 25-06-2012

Revised on: 08-07-2012

Accepted on: 15-07-2012

DO: 10.7324/J APS.2012.2724

Praveen S. Rajput, Amanjot Kaur, Navdep Kaur Gill, Karan Mittal and Ganti Subrahmanya Sarma Department of Pharmaceutical Analysis, ISF College of Pharmacy, G. T. Road, Ghal Kalan, Moga ( Punjab) -142001, Indi a.
For Correspondence Praveen S. Rajput

Email:

praveenrajputanalysis@gmail.com

\section{Simultaneous Estimation of Ramipril and Amlodipine in Bulk and tablet Dosage form by RP-HPLCMethod}

\section{Praveen S. Rajput, Amenjot Kaur, Navdeap Kaur Gill, Karan Mittal and Ganti Sulbrahmanya Sarma}

\begin{abstract}
A Simple and precise HPLC method was developed for the simultaneous estimation of Ramipril and Amlodipine in pure drug and pharmaceutical dosage forms. The separation was carried out using C18 Column $(250 \times 4.6 \mathrm{~mm}$ i.d. $5 \mu \mathrm{m}$ particle size $)$, with mobile phase compressing of Acetonitrile, Sodium phosphate buffer and Methanol in the ratio of 50: 20:25 $\mathrm{v} / \mathrm{v} / \mathrm{v}, \mathrm{pH}=6.8(\mathrm{pH}$ adjusted with OPA). The flow rate was $0.8 \mathrm{ml} / \mathrm{min}$ and the detection was carried out using PDA detector at $210 \mathrm{~nm}$. The retention times were 2.64 and 7.45 mins for Ramipril and Amlodipine respectively. Calibration curves were linear with correlation coefficient 0.998 and 0.996 over concentration range of $1-16 \mu \mathrm{g} / \mathrm{ml}$ for Ramipril and $0.2-3.2 \mu \mathrm{g} / \mathrm{ml}$ for Amlodipine respectively. Recovery was found in between $100.21 \%$ and $100.82 \%$ for Ramipril and Amlodipine respectively. Method was found to be reproducible with relative standard deviation (R.S.D) for intra and inter day precision less than $2 \%$. The method was validated by evaluation of different parameters such as accuracy, linearity, precision, LOD and LOQ.
\end{abstract}

Keywords: Ramipril (RM), Amlodipine (AM), Pantoprazole (PT), High performance liquid chromatography (HPLC), Validation.

\section{INTRODUCTION}

Ramipril (RM) chemically as (2S, 3aS, 6aS)-1-[(S)-2-[[(S)-1-(ethoxycarbonyl)-3henylpropyl]amino] propanoyl] octahydrocyclo-penta[b] pyrrole-2-carboxylic acid (Fig-1). The molecular weight of RM is 416.5 and melting point is $109^{\circ} \mathrm{C}$. Ramipril is soluble in methanol (Clarke's, 2005). It is a highly lipophilic, long acting ACE inhibitor. It inhibits angiotensinconverting enzyme which has two fold effect in reduction of angiotensin-II levels (AT-II) and increase in bradykinin levels. Both are contributes to fall in blood pressure. It acts on the reninangiotensin aldosterone system (Tripathi, 2003). It inhibits the conversion of the inactive angiotensin-I to the highly potent vasoconstrictor, angiotensin II, and also reduces the degradation of bradykinin. 


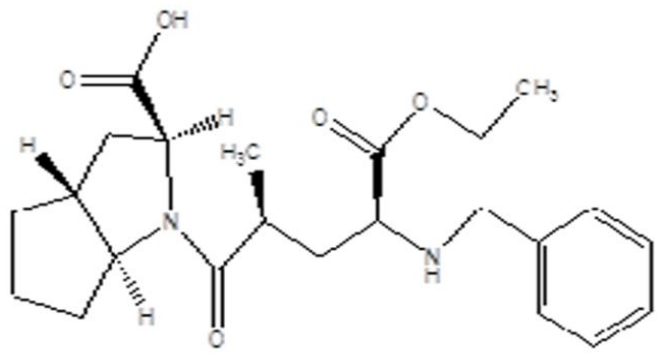

Fig. 1: Structure of Ramipril.

Ramipril is indicated for the treatment of Mild to moderate hypertension, Congestive heart failure, following myocardial infarction in patients with clinical evidence of heart failure. Amlodipine chemically as 2-[(2-Aminoethoxy) methyl]-4(2-chlorophenyl)-1,4-dihydro-6-methyl-3,5-pyridinedicarboxylic acid 3-ethyl 5-methyl ester (Fig. 2). The molecular weight of AM is 408.88 and melting point is $178^{\circ}$ to $179^{\circ} \mathrm{C}$. Amlodipine is soluble in methanol (Indian Pharmacopoeia, 2007). Amlodipine (AM) is a most distinct dihydropyridine (DHP), used as an antihypertensive and in the treatment of angina. It acts by relaxing the smooth muscle in the arterial wall, decreasing total peripheral resistance and hence reducing blood pressure; in angina it increases blood flow to the heart muscle. Amlodipine block the inward movement of calcium by binding to L-Type calcium channels in the heart and in smooth muscle of the coronary and peripheral vasculature relaxing the smooth muscle and dilating arterioles thereby decreasing peripheral resistance (Rang et al., 2008). Hence improving blood pressure; in angina it improves blood flow to them myocardium. Amlodipine, with its intrinsically long half-life alone or together with $\beta$-blocker, is likely to produce superior ischemia reduction in clinical practice.

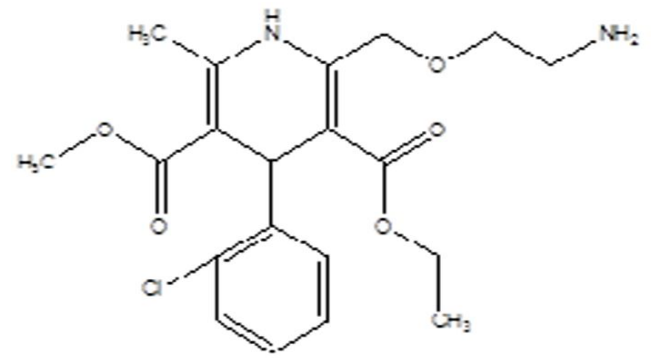

Fig. 2: Structure of Amlodipine.

A Spectrophotometric method for Analytical Method Development and Validation of Amlodipine and Hydrochlorothiazide in combined dosage form by RP-HPLC method has been reported (Anbarasi et al., 2010). Simultaneous Estimation of Ramipril and Amlodipine by UV Spectrophotometric Method has been reported (Patil et al., 2009). A Validated RPHPLC Method for Simultaneous Estimation of Nebivolol Hydrochloride and S-Amlodipine Besylate in Tablet Dosage Forms has been reported (Sudhakar et al., 2010). Analytical method development and validation of Amlodipine besylate and Perindopril erbumine in combine dosage form by RP-HPLC have been reported (Prajapati et al., 2011). A Validated RP-HPLC
Method for Simultaneous Estimation of Nebivolol Hydrochloride and S-Amlodipine Besylate in Tablet Dosage Forms has also been reported (Shah et al., 2012). Simultaneous UV Spectrophotometric Method for Estimation of Losartan Potassium and Amlodipine Besylate in Tablet Dosage Form has also been reported (Patil, et al., 2009). Simultaneous first derivative UV Spectrophotometric estimation of Ramipril and Olmesartan has also been reported (Karajgi et al., 2012). Simultaneous determination of Atenolol and amlodipine in tablets by high-performance thin-layer chromatography has also been reported (Argekar et al., 2000). Development and validation of a HPLC method for the simultaneous estimation of amlodipin and telmisartan in pharmaceutical dosage form has been reported (Shrivastava et al., 2012).

\section{EXPERIMENTAL}

\section{Reagents and materials}

$\mathrm{RM}$ and AM of Standard drug were obtained as a gift sample from Cosmas Pharmacls Ltd. (H.P., India). Marketed formulation CARDACE-AM (Batch Number-2911004, Aventis Pharma Ltd., Goa, India) with a label claim of $5 \mathrm{mg} \mathrm{RM}$ and $5 \mathrm{mg}$ AM was purchased from the local drug store of Moga, Punjab. Sodium dihydrogen ortho phosphate was of analytical grade purchased from CDH New Delhi, India. Acetonitrile and Methanol were purchased from Finar chemicals (New Delhi, India). All these chemicals and solvents were of HPLC grade and were used without any further purification. All the required solutions were prepared in HPLC grade mobile phase. Millipore water (Milli-Q, USA) was used in the preparation of buffer solution.

\section{Instrumental}

The separation was carried out using Waters 515 Series pumps combined with a PDA 2998 series photo diode array detector. The column used was C18 Column $(250 \times 4.6 \mathrm{~mm}$ i.d.; $5 \mu \mathrm{m}$ particle size). UV detection was performed at $210 \mathrm{~nm}$. Analyte weighing, for preparation of calibration standards and quality controls, was done on a microbalance, Mettler Toledo AB 204-S. All mobile phase solutions were degassed ultrasonically by Steryl 40050 bath sonicator before use. The HPLC system was controlled by a PC workstation using Empower software 2.

\section{Chromatographic conditions}

Analysis was isocratic at $0.8 \mathrm{ml} / \mathrm{min}$ flow rate with Acetonitrile: Sodium Phosphate buffer: Methanol in the ratio 50: 20:25 v/v/v, pH 6.8 ( $\mathrm{pH}$ adjusted by using OPA) as mobile phase. The mobile phase was prepared freshly every day. The mobile phase was premixed, filtered through a $0.2 \mu \mathrm{m}$ membrane filter to remove any particulate matter and degassed by sonication before use. The separation of RM and AM was good (Fig. 3) and further it was free from any interference at $210 \mathrm{~nm}$. Hence, the eluted peaks were detected at $210 \mathrm{~nm}$ for RM and AM. Moreover, the effects of different level of all these factors were systematically addressed on system suitability parameters such as resolution, theoretical plates, retention time, separation factor, asymmetry, and HETP etc. All 
mobile phase used in optimization study were prepared by mixing the Sodium phosphate buffer in water and $\mathrm{pH}$ maintained by OPA. Mobile phase was then filtered through $0.2 \mu \mathrm{m}$ membrane filter and sonicated before being used for chromatography.

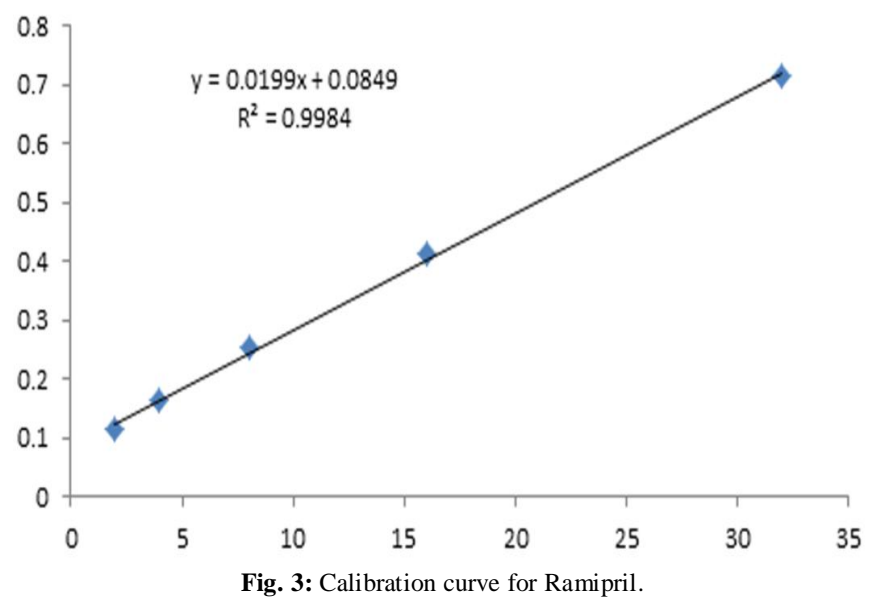

Preparation of Standard Solution

Stock solution of $10 \mathrm{mg}$ of RM standard and $10 \mathrm{mg}$ of AM standard were accurately weighed and transferred to $10 \mathrm{ml}$ volumetric flask and made up to mark with Mobile Phase, to obtain a solution of $1000 \mu \mathrm{g} / \mathrm{ml}$ of $\mathrm{RM}$ and $1000 \mu \mathrm{g} / \mathrm{ml}$ of $\mathrm{AM}$ and resultant solution was ultra sonicated for $5 \mathrm{~min}$.

\section{Analysis of test solution}

The developed method can be applied in determination of RM and AM. Cardace-AM tablets, which is marketed oral solid dosage formulation (CARDACE-AM, Batch Number-2911004, Mfg. Date October 2010, Exp. Date September 2012). Dissolve the required quantity of crushed powder of 20 tablets to make a concentration of approx $1000 \mu \mathrm{g} / \mathrm{mL}$ for $\mathrm{RM}$ or $1000 \mu \mathrm{g} / \mathrm{ml}$ for $\mathrm{AM}$ in Mobile Phase. After this the suspension formed by excipients in market formulation was centrifuged and the supernatant was collected. Test solution of market formulation was prepared by diluting required quantity of supernatant stock solution of with Mobile Phase.

\section{Optimization of chromatographic conditions}

Sometimes, the effects of different chromatographic conditions on the instrumental responses create a situation where one has to compromise between different experimental variables in order to achieve the best chromatographic separation. Chromatographic separations are significantly affected by the mobile phase conditions, such as the type and composition of the organic modifiers. The optimized chromatographic peaks with best resolution shows in Figure 3. Therefore before selecting the conditions for optimization, a number of preliminary trials were conducted with different combinations of different organic solvents and buffers at various $\mathrm{pH}$, compositions, and flow rate to check the retention time, shape, resolution, and other chromatographic parameters of RM and AM peaks individually. From those experiments the mobile phase combination of ACN, Sodium Phosphate buffer and Methanol in the acidic $\mathrm{pH}$ range was found to be more suitable. In order to achieve an optimum separation, following conditions were studied: (i) mobile phase $\mathrm{pH}$ varied at 5.6, 6.3 and 6.8 keeping the composition of ACN: Sodium Phosphate buffer: Methanol (55: 20: $25 \mathrm{v} / \mathrm{v} / \mathrm{v}$ ) and flow rate 0.8 $\mathrm{ml} / \mathrm{min}$ fixed. (ii) Mobile phase combination varied at 60:20:20 $\mathrm{v} / \mathrm{v} / \mathrm{v}, 50: 20: 30 \mathrm{v} / \mathrm{v} / \mathrm{v}$ and $70: 15: 15 \mathrm{v} / \mathrm{v} / \mathrm{v}$ with $\mathrm{pH}$ and flow rate kept constant at 6.8 and $0.8 \mathrm{ml} / \mathrm{min}$, respectively.(iii) Flow rate was varied $(0.6,0.8$, and $1.0 \mathrm{ml} / \mathrm{min})$ with mobile phase combination ( $55: 20: 25 \mathrm{v} / \mathrm{v} / \mathrm{v}$ ) and $\mathrm{pH}$ maintained at 6.8 .

\section{Validation}

Once the chromatographic method had been developed and optimized, it must be validated. The validation of an analytical method verifies that the characteristics of the method satisfy the requirements of the application domain. The proposed method was validated in the light of ICH Guidelines for linearity, precision, sensitivity, and recovery. Consequently, the following were performed (ICH Guidelines, 1996).

\section{Linearity}

The linearity of an analytical method is its ability within a definite range to obtain results directly proportional to the concentrations (quantities) of an analyte in the sample. Five different concentrations of combination of RM and AM and calibration curve were constructed in the specified concentration range. The calibration plot was generated by replicate analysis $(n=$ 5) at all concentration levels and the linear relationship was evaluated using the least square method within Microsoft Excel ${ }^{\circledR}$ program. Linearity shows in Figure 5 for RM and Figure 6 for AM.

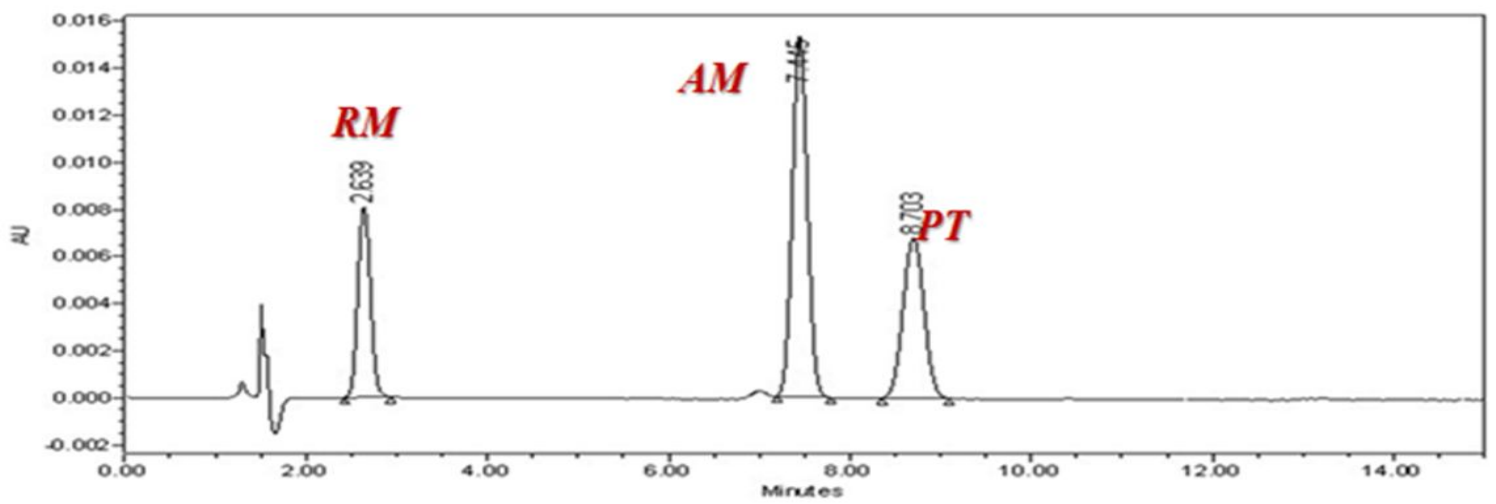

Fig. 5: Typical chromatogram of RM and AM with Internal Standard Pantoprazole (PT). 


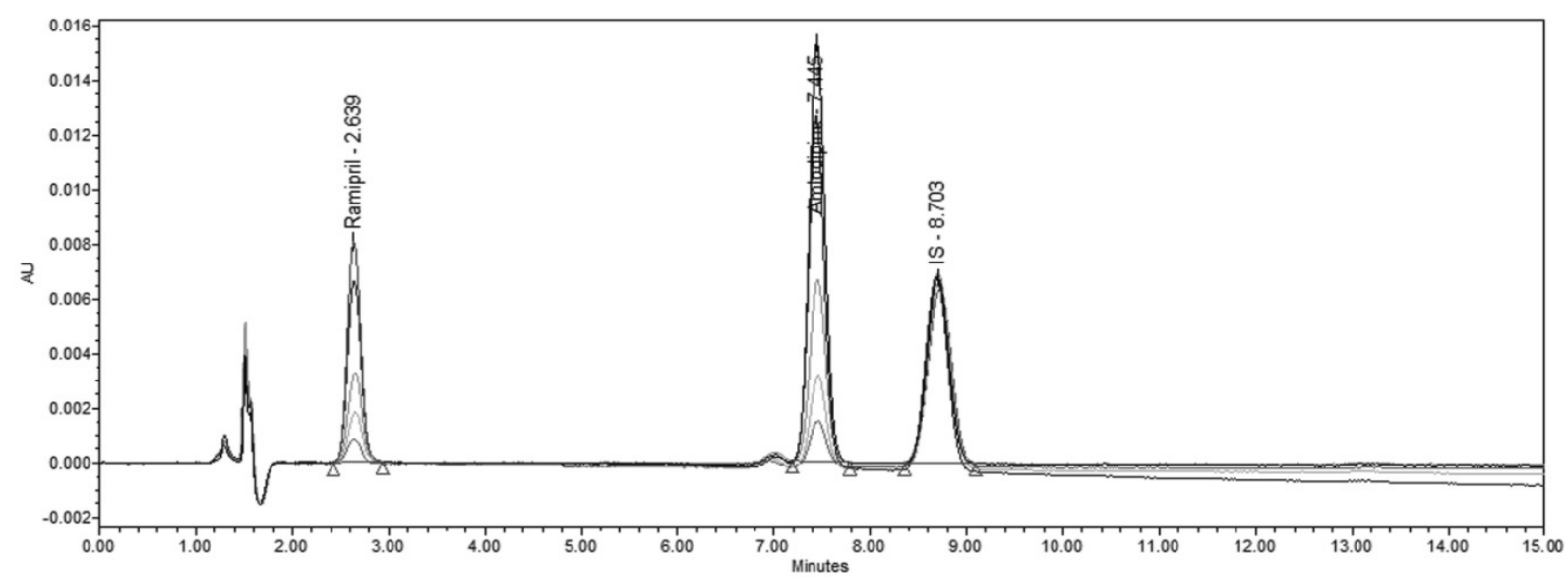

Fig. 6: Overlay chromatogram of RM and AM with Internal Standard Pantoprazole (PT).

\section{Precision}

Intra-day and inter-day precision for the analytical developed method were measured in terms of \% RSD. The experiments were repeated three times a day for intra-day precision and on three different days for inter-day precision. The concentration values for both intra-day and inter-day precision were calculated six times separately and percent relative standard deviation were calculated. Both repeatability (within a day precision) and reproducibility (between days precision) for analytical developed method were determined as follows. Solutions containing lowest, intermediate, and highest quantification concentration of the calibration curve, i.e. $2 \mu \mathrm{g} / \mathrm{ml}, 4 \mu \mathrm{g} / \mathrm{ml}, 8$ $\mu \mathrm{g} / \mathrm{ml}$ for $\mathrm{RM}$ and $0.4 \mu \mathrm{g} / \mathrm{ml}, 0.8 \mu \mathrm{g} / \mathrm{ml}, 1.6 \mu \mathrm{g} / \mathrm{ml}$ for AM were prepared. Six injections at each of the specified concentration levels were injected within the same day for repeatability, and over a period of 3 days ( 6 injections/day) for reproducibility. Mean and relative standard deviation were calculated and used to judge accuracy and precision of the method. Both intra-day and inter-day samples were calibrated with standard curves concurrently prepared on the day of analysis. Intra-day precision and inter-day precision for the developed methods were measured in terms of $\%$ R.S.D. Finally, the mean of $\%$ R.S.D. (\% R.S.D. $=[\mathrm{S} / \mathrm{X}] 100$, where $\mathrm{S}$ is standard deviation and $\mathrm{X}$ is mean of the sample analysed) were taken for conclusion.

\section{Accuracy}

For studying the accuracy of the proposed analytical method, and for checking the interference from excipients used in the dosage forms, recovery experiments were carried out by the standard addition method. This study was performed by the addition of known amounts of RM and AM to a known concentration of the commercial tablets. The amounts of standard recovered were calculated in terms of mean recovery with the upper and lower limits of percent relative standard deviation. For the determination of accuracy of the analytical procedure three identical dilutions of market formulation were spiked with different concentrations of standard solution i.e., $80 \%, 100 \%$ and $120 \%$. AUC of these solutions were then observed and plotted into calibration curve, concentration and accuracies were calculated.
Sensitivity

Limit of detection (LOD) and limit of quantitation (LOQ) were calculated by taking the AUC of standard and calculation is according to the $3.3 \mathrm{~s} / \mathrm{m}$ and $10 \mathrm{~s} / \mathrm{m}$ criterions, respectively, where "s" is the standard deviation of the AUC $(n=10)$ of the sample and " $\mathrm{m}$ " is the slope of the corresponding calibration curve.

\section{RESULTS AND DISCUSSION}

\section{Optimization of Chromatographic Condition}

The chromatographic parameters were initially evaluated using a Symmetry C18 column and a mobile phase composed of Acetonitrile: Sodium phosphate buffer: Methanol (55:20:25 v/v/v). Under these conditions, the retention time obtained for RM, AM and PT (Pantoprazole) was $2.64 \mathrm{~min}, 7.45 \mathrm{~min}$ and 8.71 respectively. (PT was used as an internal standard). Optimized chromatographic peak shows in Figure 3. The mobile phase composed of Acetonitrile: Sodium phosphate buffer: Methanol $(55: 20: 25 \mathrm{v} / \mathrm{v} / \mathrm{v})$ promoted an adequate separation $(\mathrm{RT}=2.64$ for $\mathrm{RM}, \mathrm{RT}=7.45$ for $\mathrm{AM}$ and 8.7 for PT). So, this condition was adopted in subsequent analyses.

\section{System Suitability Parameter}

System suitability tests, an integral part of a chromatographic analysis are used to verify that the resolution and reproducibility of the chromatographic system are adequate for the analysis. A system suitability test according to ICH was performed on the chromatograms obtained from standard and test solutions to check different above mentioned parameters and the results obtained from six replicate injections of the standard solution are summarized in the Table 1.

Table. 1: System suitability parameter of analytical method

\begin{tabular}{ccccc}
\hline \multirow{2}{*}{ S. No. } & \multirow{2}{*}{ Parameters } & RM & AM & PT \\
\cline { 4 - 5 } & & & 7.51 & \\
\hline 1 & Selectivity & & 17.03 & \\
2 & Resolution & 2.6 & 7.5 & 8.7 \\
3 & Retention time & 1.07 & 1.05 & 1.01 \\
4 & Tailing factor & 2730.37 & 9422.09 & 6508.36 \\
5 & Plate count & 2.39 & 2.92 & 3.41 \\
6 & Capacity factor & & & \\
\hline
\end{tabular}




\section{Validation}

\section{Linearity/Calibration Curve}

A linear correlation was found between the peak areas and the concentrations of RM and AM, in the range of 1-16 $\mu \mathrm{g} / \mathrm{ml}$ for $\mathrm{RM}$ and $0.2-3.2 \mu \mathrm{g} / \mathrm{ml}$ for AM. The regression analysis data are presented in Table 2 the regression coefficients $\left(\mathrm{r}^{2}\right)$ obtained for RM 0.998 and for AM 0.996. Both compounds show the linearity of the method. Calibration curve for RM given in figure 3 and for AM given in Figure 4.

Table 2: Regression Analysis data for the developed method.

\begin{tabular}{lcc}
\multicolumn{1}{c}{ Parameters } & \multicolumn{2}{c}{ Data } \\
\cline { 2 - 3 } & No interference at retention time of the \\
analyte \\
Specificity & \multicolumn{2}{c}{ AM } \\
Linearity range $(\mu \mathrm{g} / \mathrm{ml})$ & $1-16$ & $0.2-3.2$ \\
Absorption maxima, $\lambda$ max $(\mathrm{nm})$ & 210 & 210 \\
Coefficient of regression $\left(\mathrm{r}^{2}\right)$ & 0.998 & 0.996 \\
Equation of Regression line & $\mathrm{Y}=0.019 \mathrm{x}+0.084$ & $\mathrm{Y}=0.763 \mathrm{x}+$ \\
& & 0.062 \\
Slope & 0.019 & 0.763 \\
Intercept & 0.084 & 0.062 \\
LOD $(\mathrm{ng} / \mathrm{ml})$ & 150 & 36 \\
LOQ $(\mathrm{ng} / \mathrm{ml})$ & 495 & 118.8 \\
$\%$ Recovery & 100.21 & 100.82 \\
\hline
\end{tabular}

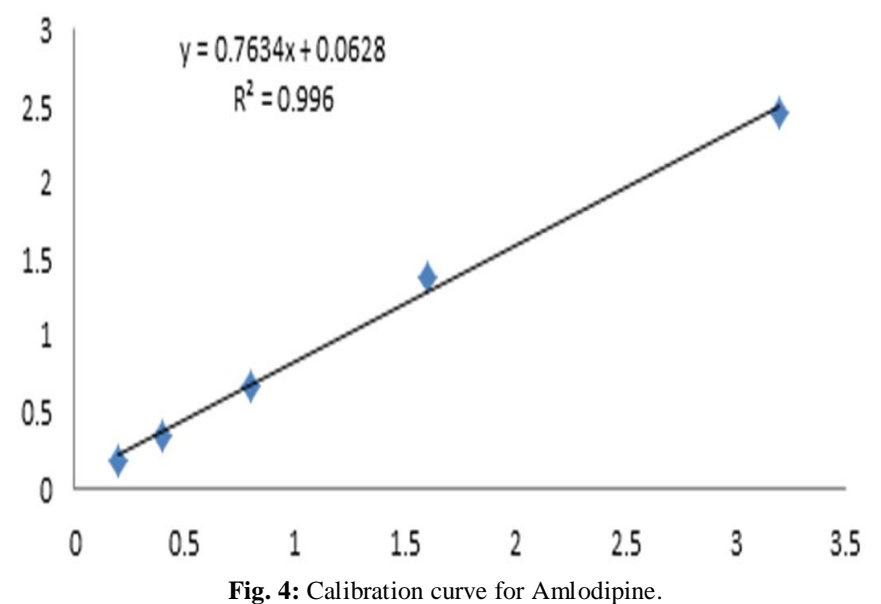

\section{Precision}

The concentration values for both intra-day precision and inter-day precision of analytical method were calculated six times separately and percent relative standard deviation were calculated, as shown in Table 3 (a) for Ramipril and Table 3 (b) for Amlodipine.

Table. 3 (a): Precision data of Ramipril.

\begin{tabular}{cccc}
\hline Sr. No. & Conc. $(\boldsymbol{\mu g} / \mathbf{m L})$ & Intraday (\% RSD) & Interday (\% RSD) \\
\hline 1 & 2 & 0.057 & 0.057 \\
2 & 4 & 0.217 & 0.056 \\
3 & 8 & 0.052 & 0.048 \\
& Mean & 0.107 & 0.054 \\
\hline
\end{tabular}

Table. 3 (b): Precision data of Amlodipine

\begin{tabular}{cccc}
\hline Sr. No. & Conc. $(\boldsymbol{\mu g} / \mathbf{m L})$ & Intraday (\% RSD) & Interday (\% RSD) \\
1 & 0.4 & 0.022 & 0.393 \\
2 & 0.8 & 0.147 & 0.094 \\
3 & 1.6 & 0.131 & 0.119 \\
& Mean & 0.100 & 0.202 \\
\hline
\end{tabular}

\section{Accuracy}

It was investigated by means of addition of RM and AM reference standards to a mixture of the tablet excipients. RM mean recovery $(\mathrm{n}=9)$ was $100.22 \%$ and AM mean recovery was $100.82 \%$ demonstrating the accuracy of the method.

\section{Specificity}

Peaks obtained for RM and AM in the chromatograms of sample solutions, demonstrating that other compounds did not coelute with the main peaks. The chromatogram obtained with the mixture of the tablet excipients showed no interfering peaks in the same retention time of RM and AM figure 5.

\section{Detection and quantitation limits}

According to the determined signal-to-noise ratio, RM limits of detection of $150 \mathrm{ng} / \mathrm{ml}$ and limits of quantitation of 495 $\mathrm{ng} / \mathrm{ml}$ and $\mathrm{AM}$ limits of detection of $36 \mathrm{ng} / \mathrm{ml}$ and limits of quantitation of $118.8 \mu \mathrm{g} / \mathrm{ml}$ respectively. However, the objective of the method is the simultaneous quantitation of RM and AM, so that the values obtained for RM should be considered as the limit of method sensitivity. Hence, the detection limit established was 150 $\mathrm{ng} / \mathrm{ml}$ of $\mathrm{RM}$ and $36 \mathrm{ng} / \mathrm{ml}$ of $\mathrm{AM}$ and the quantitation limit was $495 \mathrm{ng} / \mathrm{ml}$ of $\mathrm{RM}$ and $118.8 \mu \mathrm{g} / \mathrm{ml}$ of $\mathrm{AM}$, the same compounds proportion found in the sample solutions injected onto the chromatograph.

\section{Analysis of fixed dose combination tablets}

Samples of fixed dose combination tablets (Cardace-AM) containing $5 \mathrm{mg}$ of RM and $5 \mathrm{mg}$ of AM were analyzed using the validated method. All analyzed batches presented RM and AM contents very close to the labeled amount. The RM content in the tablet samples varied from $99.80 \%$ to $103.35 \%$, while AM content varied from $98.98 \%$ to $100.48 \%$. The development of simple and reliable methods is essential to assure the identification and quantitative determination of antihypertensive drugs, since the problem of counterfeit or substandard antihypertensive is well established all over the world.

\section{CONCLUSION}

The proposed method was found to be simple, fast, roboust, more precise and accurate under the present experimental conditions. Therefore the developed method can be used for routine analysis for simultaneous estimation of Ramipril and Amlodipine in bulk and pharmaceutical dosage form.

\section{ACKNOWLEDGEMENTS}

Drugs were procured from Cosmas Pharmacls Ltd., H.P. (India). Authors are greatly thankful to the Chairman Sh. Parveen Garg and management of ISF college of Pharmacy and Lab incharge of ISFAL for providing HPLC facility.

\section{REFERENCE}

Anbarasi B., Safeer K. and Senthil Kumar N. Analytical Method Development and Validation of Amlodipine and 
Hydrochlorothiazide in combined dosage form by RP-HPLC, International Journal of ChemTech Research, 2010; 2: 21-25.

Argekar A. P. and Powar S. G. Simultaneous determination of atenolol and amlodipine in tablets by high-performance thin-layer chromatography. J. Pharm. Biomed. Anal. 2000; 21: 1137-1142.

Clarke's Analysis of Drugs and Poisons, Publications division of the Royal Pharmaceutical Society of Great Britain, $3^{\text {rd }}$ Ed. 2005.

ICH Guidelines, Text on Validation of Analytical ProceduresMethodology (ICH Q2A) 1996.

Indian Pharmacopoeia.; Ministry of Health \& Family Welfare; Indian Pharmacopoeia Commission.; Ghaziabad, $4^{\text {th }}$ Ed. 2007; 3; 10341035.

Karajgi R. Santosh, Simpi C.C. and Kalyane N.V. Simultaneous first derivative UV spectrophotometric estimation of ramipril and olmesartan, RGUHS J Pharm Sci., 2012; 2 (1): 78-82.

Patil R Priyanka, Rakesh U Sachin, Dhabale N Pandurang, and Burade B Kishor. Simultaneous Estimation of Ramipril and Amlodipine by UV Spectrophotometric Method, Research J. Pharm. and Tech. 2009; 2 (2): 304-307.

Patil R. Priyanka, Rakesh U. Sachin, Dhabale N. Pandurang and Burade B. Kishor. Simultaneous UV Spectrophotometric Method for Estimation of Losartan Potssium and Amlodipine Besylate in Tablet Dosage Form, Asian J. Research Chem. 2009; 2 (1): 183-187.

Prajapati Jignesh, Patel Ajay, Patel M. B., Prajapati Nimesh and
Prajapati Rashmika. Analytical method development and validation of Amlodipine besylate and Perindopril erbumine in combine dosage form by RP-HPLC, International Journal of PharmTech Research, 2011; 3: 801808.

Rang H. P., Dale M. M., Ritter J. M. and Flower R. I. Antibacterial drug: In Rang and Dale Pharmacology $6^{\text {th }}$ edition, Churchill Livingstone Elsevier publication, 2008

Shah Rikin, Modi Mayur and Mashru Rajashree. Development and Validation of Spectrophotometric Methods for Simultaneous Estimation of Amlodipine Besilate and Indapamide in Combined Pharmaceutical Formulation, International Journal of Pharmacy and Pharmaceutical Sciences, 2012; 4 (2): 695-698.

Shrivastava K. Sushant, Sinha K. Saurabh, Shrivastava K. Prabhat. Development and validation of a HPLC method for the simultaneous estimation of amlodipin and telmisartan in pharmaceutical dosage form, Asian Pacific Journal of Tropical Biomedicine, 2012; 312315 .

Sudhakar M., Venkateshwara Rao J., Devika G.S. and Petchi R. Ramesh. A Validated RP-HPLC Method for Simultaneous Estimation of Nebivolol Hydrochloride and S-Amlodipine Besylate in Tablet Dosage Forms, International Journal of Chemical and Pharmaceutical Sciences, 2010; 1 (2): 28-33.

Tripathi K. D., Essential of Medical Pharmacology. Fifth ed. Jaypee Brothers Medical Publishers (P) Ltd, New Delhi. (2003): 48-52. 